\title{
Estimating the Energy Density of Fish: The Importance of Ontogeny
}

\author{
Mark J. Wuenschel, ${ }^{1}$ Amelia R. Jugovich, and Jonathan A. Hare ${ }^{2}$ \\ National Oceanic and Atmospheric Administration, National Ocean Service, Center for Coastal Fisheries \\ and Habitat Research, 101 Pivers Island Road, Beaufort, North Carolina 28516, USA
}

Abstract.- Ontogenetic patterns in the percent dry weight (\%DW) and energy density (joules per gram of wet weight) were studied in the early life stages of the subtropical estuarine and marine gray snapper Lutjanus griseus and the warmtemperate estuarine and marine spotted seatrout Cynoscion nebulosus. The \%DW was variable for individuals of both species but increased significantly through larval to juvenile stages $(<20 \%$ for fish $<50 \mathrm{~mm}$ standard length to $20-30 \%$ for fish $>50 \mathrm{~mm}$ ). The lipid percentage, which was determined only for gray snapper, was also variable between individuals but showed significant increase with body size. Strong relationships between percent dry weight and energy density were evident for both species; however, the slopes of regressions were significantly lower than in general multispecies models, demonstrating the need for species- and stagespecific energy density data in bioenergetics models.

Modeling energy flow in aquatic ecosystems has been used to evaluate the interrelationships between fish and their prey and between fish and their environment (e.g., Stewart and Binkowski 1986; Brandt and Kirsch 1993; Lantry and Stewart 1993; Rand and Stewart 1998). Important components of bioenergetic models are the energy density (ED; joules per gram of wet weight) of both predator and prey. The energy density of individual fish and fish populations varies seasonally (Flath and Diana 1985), ontogenetically (Deegan 1986; Sogard and Spencer 2004) and spatially (Schultz and Conover 1997). Bomb calorimetry is a reliable method for measuring the energy content of fish and may be preferable to estimates based on proximate analysis (Craig 1977), but it is time consuming. Further, even the smallest microbomb instruments require several milligrams of dried material, limiting applications to smaller samples (e.g., early

\footnotetext{
* Corresponding author: wuensche@marine.rutgers.edu

${ }^{1}$ Present address: Rutgers University, Institute of Marine and Coastal Sciences, Marine Field Station 800, c/o 132 Great Bay Boulevard, Tuckerton, New Jersey 08087-2004, USA.

${ }^{2}$ Present address: National Oceanic and Atmospheric Administration, National Marine Fisheries Service, Northeast Fisheries Science Center, Narragansett Laboratory, 28 Tarzwell Drive, Narragansett, Rhode Island 02882, USA.
}

Received December 22, 2004; accepted October 20, 2005 Published online February 8, 2006 life stages). As a result, energy density data for specific species and life stages is often lacking, leading to the borrowing of energy density data from other species and life stages in bioenergetics models.

Strong positive relationships between energy density and percent dry weight (often at $r^{2}>0.90$ ) have been reported for many species. These relationships enable the estimation of energy density from percent dry weight for greater numbers of fish because measurement of energy density through direct bomb calorimetry is time consuming (Rand et al. 1994; Hartman and Brandt 1995; Lantry et al. 1999). The positive relationship between energy density and percent dry weight results from the differential rates of deposition and utilization of water and lipid; in later life stages during periods of starvation, lipids are used faster than water, resulting in decreased percent dry weight and energy density. Although the percent dry weight method has proven reliable for tracking the changes in energy density of large juveniles and adults at the seasonal and population level (Stewart and Binkowski 1986; Rand et al. 1994; Hartman and Brandt 1995; Johnson et al. 1999), the ontogeny of \%DW-ED relationship in the early life stages of many fishes remains unclear.

Energy allocation strategies in larvae and juveniles may be fundamentally different from those of subadults and adults; therefore, estimating energy density from general ED-\%DW relationships may be inappropriate for early life stages and may introduce significant error in energetics models. The \%DW-ED relationship during early life stages is probably less influenced by the deposition of lipids compared with other body constituents (bone, scale, muscle). The initial energy density of larvae is dependent on, among other things, the amount of energy incorporated in the egg (Trippel et al. 1997). As larvae begin exogenous feeding and grow, they face the tradeoff between energy storage, which increases their energy density and starvation resistance, and somatic growth (Post and Parkinson 2001). Energy allocation strategies that favor growth over storage would benefit fishes, particularly early life stages, facing size selective forces such as predation (Sogard 1997); however, other size-selective forces such as overwinter mortality may favor storage rather 
than growth (Henderson et al. 1988; Thompson et al. 1991; Schultz and Conover 1999; McCollum et al. 2003). Therefore, because of ontogenetic changes in body form and composition, estimation of energy density from ED-\%DW relationships derived for other species and life stages may introduce significant errors into bioenergetics models. The goal of this study was to determine the energy density for the early life stages of the subtropical estuarine and marine gray snapper Lutjanus griseus and the warm-temperate estuarine and marine spotted seatrout Cynoscion nebulosus. The $\%$ DW-ED relationships for these two species are compared with published summary equations in an effort to characterize ontogenetic patterns in the $\%$ DW-ED relationship.

\section{Methods}

Gray snapper.-Juvenile gray snapper were analyzed from a variety of sources (Table 1). Ingressing larvae and juveniles were collected near Beaufort, North Carolina (following Tzeng et al. 2003 and Wuenschel et al. 2004). Larger juveniles were also collected from Core Sound, and Newport River estuary, North Carolina, using a 3-m otter trawl and beach seine. All gray snapper analyzed from North Carolina were collected from August 2003 through October 2003. Additional samples of gray snapper juveniles were collected from Biscayne Bay, Florida, from June 2003 through February 2004 using an otter trawl and beach seine. In all cases, gray snapper were separated from the catch, placed on ice in the field, and transferred to freezer upon return from the field. Frozen samples from Florida were shipped overnight to National Oceanic and Atmospheric Administration (NOAA) Beaufort Laboratory for wet weight-dry weight (WW-DW) analysis. Fish were thawed, and standard length (SL; nearest $0.5 \mathrm{~mm}$ ), and WW on an electronic balance were recorded (nearest $0.01 \mathrm{~g}$ or $0.0001 \mathrm{~g}$, depending on fish size). The fish stomachs were dissected and their contents were removed and

TABLE 1.-Gray snapper and spotted seatrout samples analyzed for energy density summarized by standard length, number of fish examined $\left(N_{F}\right)$, and number of samples analyzed $\left(N_{S}\right)$

\begin{tabular}{lccc}
\hline \multicolumn{1}{c}{ Location } & SL $(\mathrm{mm})$ & $N_{F}$ & $N_{S}$ \\
\hline & Gray snapper & & \\
Biscayne Bay, Florida & $20-115$ & 42 & 41 \\
Core sound, North Carolina & $12-58$ & 10 & 6 \\
Beaufort Inlet, North Carolina & $11.5-13$ & 34 & $3^{\text {a }}$ \\
\multicolumn{4}{c}{ Spotted seatrout } \\
Florida Bay, Florida & $14.5-67$ & 420 & 145 \\
Laboratory reared & $9.2-9.7$ & 120 & $9^{\text {a }}$ \\
\hline
\end{tabular}

${ }^{\mathrm{a} C}$ Composite samples. weighed; the fish and their empty stomachs were then placed on previously weighed aluminum pans and dried to a constant weight at $60^{\circ} \mathrm{C}$. Fish wet weights were corrected by subtracting the weight of the stomach contents.

Energy density of gray snapper was determined by gravimetric analysis of lipid content following Schultz and Conover (1997). Dried fish were placed in individual preweighed extraction thimbles and cut into small pieces to facilitate extraction of lipids. Thimbles were placed in individual Soxhlet extractors and run for $4 \mathrm{~h}$ with petroleum ether as the solvent. Preliminary trials indicated this period to be sufficient because additional lipids would not be extracted beyond $4 \mathrm{~h}$ (J. Morley and J. Buckel, North Carolina State University, personal communication). After extraction, samples were redried for $48 \mathrm{~h}$ at $60^{\circ} \mathrm{C}$ to determine the lipid free (lean) dry weight. The lean samples were then placed in a muffle furnace at $450^{\circ} \mathrm{C}$ for $24 \mathrm{~h}$ and cooled to $70^{\circ} \mathrm{C}$, after which final ash weight was determined. Using energy-equivalent values for lipid (39.54 J/g) and lean tissue $(20.08 \mathrm{~J} / \mathrm{g})$, we then calculated the total energy of individual fish from the amounts of lipid and lean tissue. These values were obtained by converting the caloric values from Brett and Groves (1979; 9.45 $\mathrm{kcal} / \mathrm{g}$ lipid and $4.80 \mathrm{kcal} / \mathrm{g}$ lean) to joules by assuming $1 \mathrm{cal}=4.184 \mathrm{~J}$ (Schmidt-Nielson 1997).

Spotted seatrout.-Larval and juvenile spotted seatrout were collected in the vicinity of Bradley Key, Florida Bay in 1999 and 2000 (Table 1). Spotted seatrout were collected with a benthic sled $(1.0 \times 0.5$ $\mathrm{m}, 0.947-\mathrm{mm}$ mesh), immediately frozen in water over dry ice, and stored frozen in water until WW-DW analysis in the laboratory, which was performed in the same manner as for gray snapper. Energy density of spotted seatrout was determined using a Phillipson Oxygen Microbomb Calorimeter. Dried fish were ground to a uniform particle size in a ceramic mortar and pestle, and formed into pills. The micro-bomb was calibrated using a benzoic acid standard (following Phillipson 1964), and the calibration was checked after every 40-45 determinations. The number of bomb determinations per individual was dependant on fish size. Some of the smaller fish only contained enough material for one or two determinations, whereas values for larger fish represent an average of three determinations. In some cases it was necessary to combine several small fish to obtain enough material to analyze. In these cases, fish were pooled based on similar sizes ( $\pm 2 \mathrm{~mm} \mathrm{SL}$ ) and percent dry weight ( $\pm 1 \% \mathrm{DW})$. In addition, groups of laboratory-reared larvae were analyzed to obtain energy density values of fish smaller than those collected with the benthic sled (six pooled samples of 20 larvae, Table 1). 
Statistical analysis.-Least-squares linear regression was used to determine the relationship between energy density and percent dry weight for each species. The slopes of the two species-specific ED-\%DW models were compared with each other using paired, two-tailed $t$-tests; significance set at $\alpha=0.05$.

\section{Results}

\section{Percent Dry Weight and Lipid Percentage}

The percent dry weight for individuals of both species was highly variable (Figure 1a, b); however, a general trend of increasing percent dry weight with increasing fish size was apparent. Although the $r^{2}$ values were low for the \%DW versus length for both species, the nonlinear regression model parameters were significantly different than zero in both cases $(P$ $<0.001)$. The percent dry weight of both species increased from levels generally below $20 \%$ for individuals less than $50 \mathrm{~mm} \mathrm{SL}$, to $20-30 \%$ for individuals greater than $50 \mathrm{~mm}$ SL. The lipid percentage for gray snapper was also variable (Figure $2)$; however the increased lipid percentage with length was significant $(P=0.0011)$.

\section{Energy Density of Gray Snapper and Spotted Seatrout}

The energy density of both species increased significantly in relation to $\% \mathrm{DW}(P<0.001$; Figure $3)$, and species-specific regressions were developed to predict energy density from percent dry weight. The slope of the ED-\%DW relationship for gray snapper was significantly greater than the slope for spotted seatrout ( $t$-test, $P=0.0044$ ). The slopes for both gray snapper (208.92) and spotted seatrout (162.68) were lower than those reported by Hartman and Brandt (1995) for their combined-species model (375) and Perciformes model (309.5). Spotted seatrout also had a lower slope than that for age-0-2 weakfish Cynoscion regalis (319.4; Hartman and Brandt 1995).

\section{Discussion}

Percent dry weight has been shown to vary according to various aspects of fish life history and nutritional status (Love 1980) and has been used to model the energy dynamics of fishes (Stewart and Binkowski 1986; Rand et al. 1994; Hartman and Brandt 1995). Generally, there is a linear relation between percent dry weight and oil content (lipid), which in part drives the linear relation between energy content and percent dry weight. The ED-\%DW relationships presented here for young gray snapper and spotted seatrout, however, had lower slopes than the general linear models presented by Hartman and Brandt (1995) and were lower than the predictions
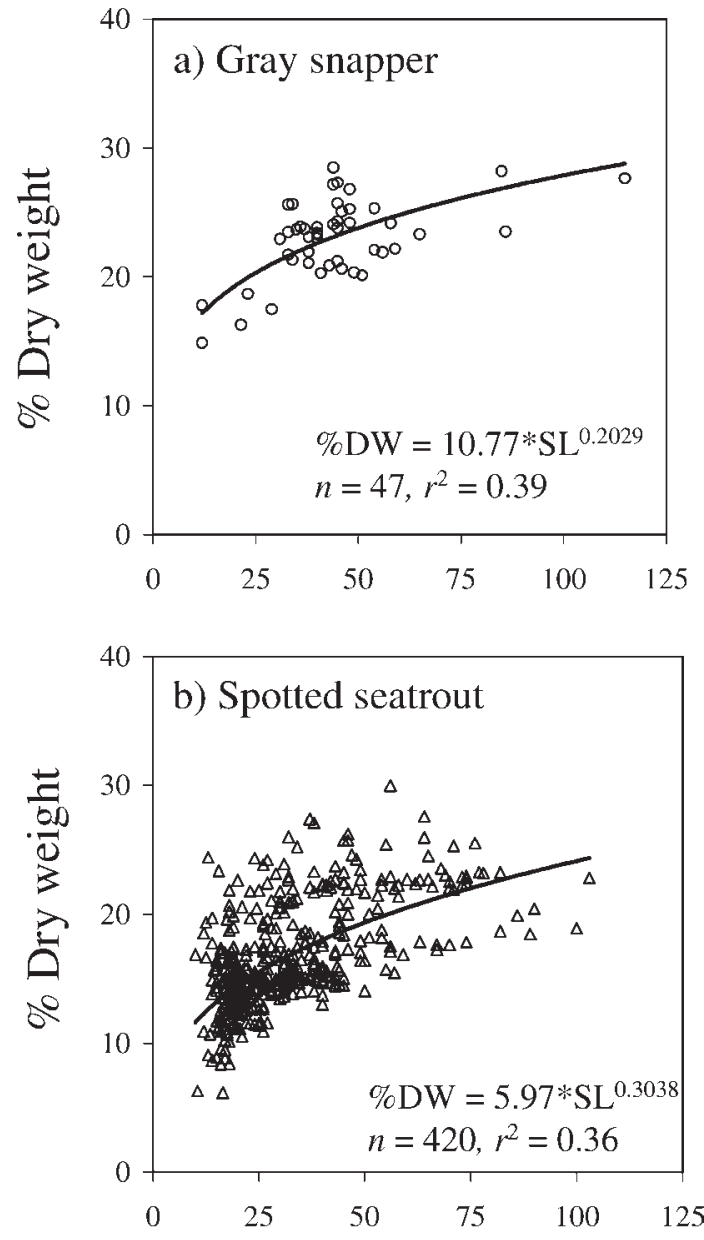

\section{Standard length (mm)}

FIGURE 1.-Ontogenetic increase in percent dry weight (\%DW) with standard length (SL) for gray snapper (North Carolina and Florida) and spotted seatrout (Florida and laboratory reared).

from both their curvilinear model and that of Schreckenbach et al. (2001; Figure 3). In many fishes, lipid levels remain low throughout larval and early juvenile stages, before abruptly increasing in later juvenile stages. For example, the threshold for increasing accumulation of triacyl-glycerols (key storage lipids) begins at about $40 \mathrm{~mm} \mathrm{SL}$ in black sea bass Centropristis striata, at about $50 \mathrm{~mm}$ SL in scup Stenotomus chrysops, and at about 120 SL in northern kingfish Menticirrhus saxatilis (V. Guida, NMFS, Sandy Hook, New Jersey, personal communication). Similarly, in young weakfish weight-specific levels of triacyl-glycerols remained a low percentage of dry 


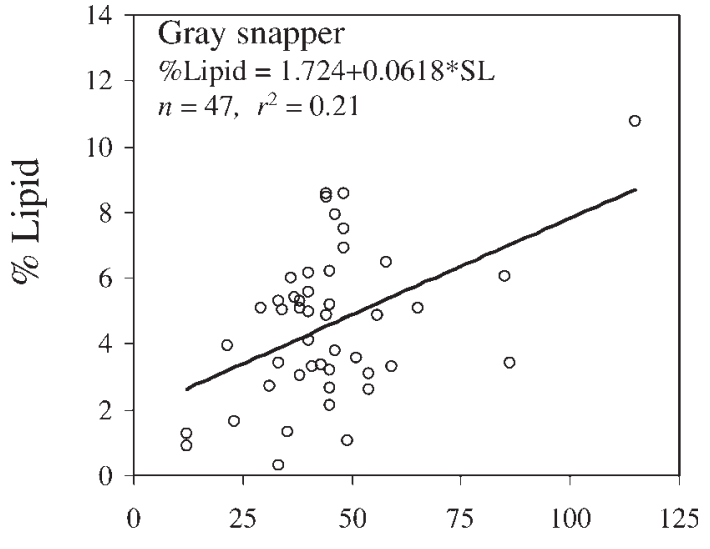

\section{Standard length (mm)}

FIGURE 2.-Lipid percentage of gray snapper from North Carolina and Florida in relation to standard length (SL).

mass until juveniles reached a size of about $100 \mathrm{~mm}$ SL, when fish began to store more lipids (Litvin 2005). Such increases in the percent lipid may be associated with ontogenetic changes in diet, and the preparation for overwintering or migration. The tradeoff between energy storage and growth is important for young fish that need to grow rapidly to escape predation pressure (Sogard 1997) while concurrently accumulating enough reserves to survive periods of decreased food abundance or migration. Schultz and Conover (1997) showed that high-latitude populations of Atlantic silversides Menidia menidia had higher rates of energy storage than low-latitude populations, which was a response to size-dependent overwinter mortality. Although overwinter mortality should be less of a problem for subtropical species such as gray snapper and spotted seatrout, the more diverse array of potential predators may be more important for fish at lower latitudes than starvation. We might expect that species inhabiting subtropical estuaries, in which food abundance is more stable seasonally, would allocate as much energy as possible into growth, leaving little for storage. Juvenile gray snapper and spotted seatrout occupy similar habitats, have similar diets, and both undergo ontogenetic diets shifts from copepod, amphipod, and mysid prey as small juveniles to shrimp and fish prey as larger juveniles (Hettler 1989).

The generally lower lipid levels present in larval and juvenile fishes may explain, in part, the lower slope in the relationship between percent dry weight and energy density for young spotted seatrout and gray snapper in our study. The lower slope for spotted seatrout in relation to the more northerly distributed congeneric weakfish may be due to several factors: (1) the weakfish data of Hartman and Brandt (1995) is for age-0 to age- 2 fish, therefore including larger fish than the spotted seatrout data; (2) the weakfish were collected farther north (Maryland) than the spotted seatrout (Florida Bay); and (3) despite being congenerics, differences in life histories of the two species exist (i.e., juvenile weakfish migrate offshore from estuarine nursery areas whereas spotted seatrout do not). The comparison between these two species underscores the potential importance of obtaining species and life-stage-specific energy density values for use in bioenergetics models.

Although percent dry weight may be an indicator of condition in young fish, increases in percent dry weight may not be due to increases in high-energy lipids but to the lower-energy-content somatic tissue. In contrast to larger juveniles and adults, in which increases in percent dry weight are indicative of increases in percent lipid, the ontogenetic increase in percent dry weight during early life stages may be associated with increases in components other than lipid (i.e., ossification of bones and scales). This may explain the lower slope in the relationship between percent dry weight and energy density for young gray snapper and spotted seatrout. Thayer et al. (1973) similarly found lower values of percent dry weight and energy content in juveniles versus adults of several estuarine species. Their study only reported single estimates for energy density and percent dry weight for each species and life stage, thereby precluding estimation of the slope of the ED-\%DW relationship within a life stage for each species. However, an inspection of their data grouped by life stage revealed a lower slope in the ED-\%DW relationship for juveniles versus adults. Therefore, it is important that a distinction be made when comparing the slope of the ED-\%DW relationship within and between species. The relationships between percent dry weight and energy density reported here $\left(r^{2}=0.76-\right.$ 0.91 ) are lower than those reported for other species. This is primarily due to two factors: (1) young fish have proportionately less fat and lipids, resulting in a lower slope in the ED-\%DW relationship; and (2) errors associated with accurate determination of WW of small samples (and therefore percent dry weight) will lead to increased variability in the ED-\%DW relationship.

The percent dry weight was highly variable for individuals (Figure 1). Deegan (1986) also found lower and more variable percent dry weight in larvae versus juvenile and subadults. The power functions through the scatter of percent dry weight data for both gray snapper and spotted seatrout had a low $r^{2}$ values because of the large variability among individuals. Errors in the percent dry weight may be more 

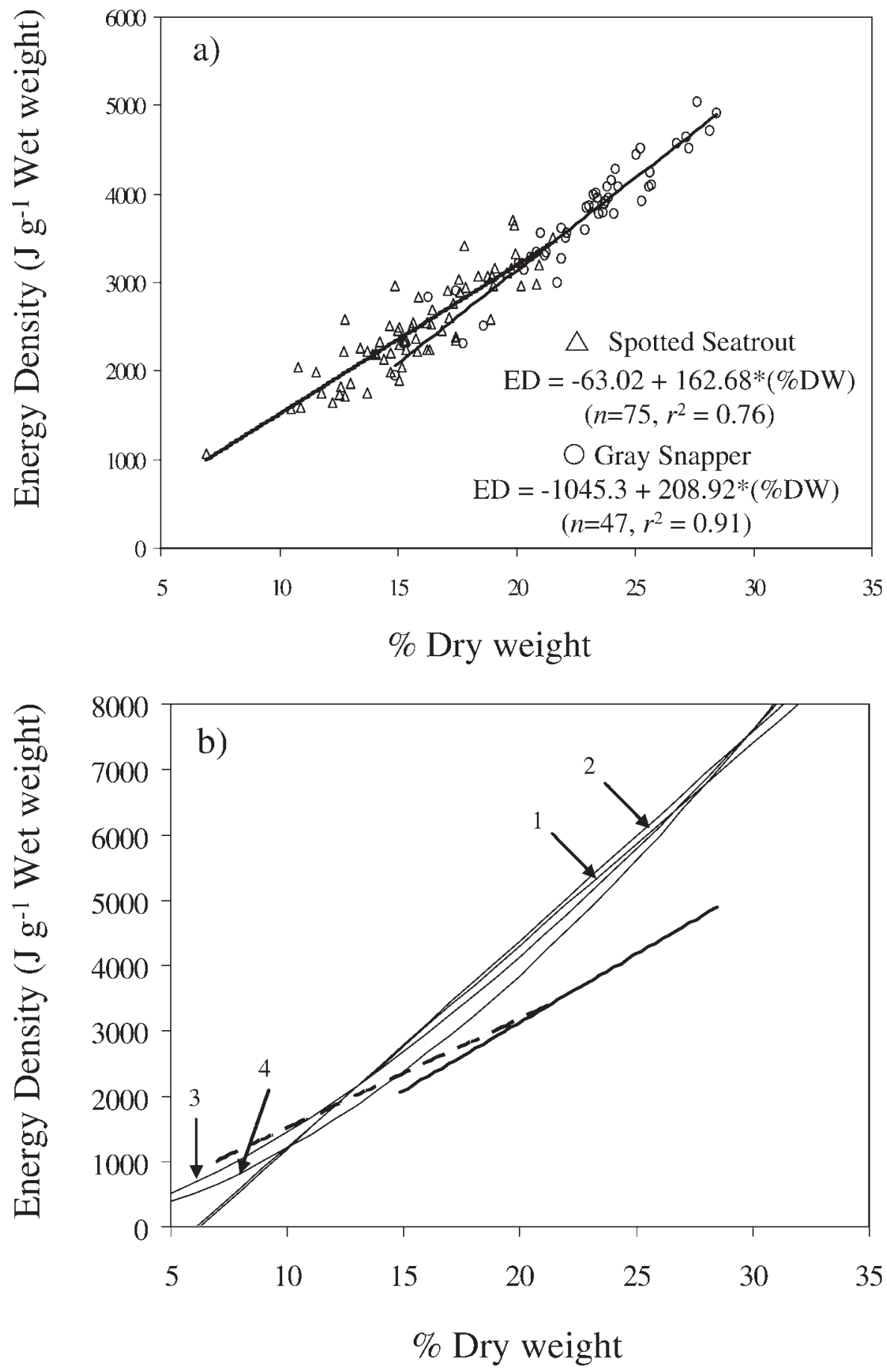

FIGURE 3.- Panel (a) shows the relationships between percent dry weight (\%DW) and energy density (ED) for gray snapper and spotted seatrout. Panel (b) shows the regression lines from panel (a) plotted with predicted energy densities from the Hartman and Brandt (1995) models for (1) Perciformes (ED $=-1,875+309.5 \%$ DW), (2) weakfish $(\mathrm{ED}=-1,997+$ 319.4.\%DW), (3) their combined-species model $\left(\mathrm{ED}=45.29 . \% \mathrm{DW}{ }^{1.507}\right.$ ) and (4) the Schreckenbach et al. (2001) model for freshwater fishes $\left(\mathrm{ED}=25.3 \cdot \% \mathrm{DW}^{1.6783}\right)$. 
influenced by either WW or DW determinations, depending on fish size. Whereas percent dry weight can be measured with high precision for juveniles and adults of many species, its application to fish larvae is limited by the ability to obtain accurate WW for small individuals, in contrast to the difficulty in obtaining accurate DW for large individuals. Some of the variability in $\% \mathrm{DW}$ is probably due to measurement errors; nevertheless, the data indicate a nonlinear increase in percent dry weight through early life stages for both species. The gradual increase in energy content is typical of many larval and juvenile fishes; however, in species that undergo dramatic transformations, the relationship may be more complex. Larval Senegal sole Solea senegalensis showed an increase in energy density to levels higher than typical for most marine larvae (Yúfera et al. 1999); the energy content subsequently declined as these energy reserves were used up during metamorphosis. This build up of reserves may be important in flatfishes, many of which do not feed during metamorphosis (Tanaka et al. 1996).

It is apparent from Figure 3 that estimating the energy density of early life stages from the general multispecies \%DW-ED relationships developed from later life stages may lead to overestimates of up to $25 \%$. The magnitude of this error increases with $\% \mathrm{DW}$, and is significant for fish of about $20-30 \% \mathrm{DW}$, which corresponds to about $50-100 \mathrm{~mm}$ SL for gray snapper and spotted seatrout. Because energy is the common currency used to balance energy budgets, biases and errors in energy density will be propagated in subsequent estimates of consumption or growth. For example, if energy density of a fish (as predator) being modeled is overestimated by about $25 \%$, consumption would likewise be overestimated to provide the energy intake to attain observed growth. Conversely, if energy density of fish (as prey) is overestimated by about $25 \%$, estimates of consumption (and impact on prey populations) would be underestimated. Bioenergetic models for the early life stages of fishes should therefore include appropriate stage-specific energy density values to avoid potentially significant errors.

\section{Acknowledgments}

The authors thank M. LaCroix, M. Greene, and B. Degan (NOAA, Center for Coastal Fisheries and Habitat Research) for help collecting spotted seatrout in Florida Bay and gray snapper in Core Sound; G. T. Kellison (National Park Service, Biscayne Bay) and J. Hall (NOAA, Southeast Fisheries Science Center) for providing gray snapper from Biscayne Bay; and J. Buckel and J. Morley (North Carolina State University, Center for Marine Sciences and Technology) for use of Soxhlet extraction columns. We also thank G. Thayer, J. Buckel, P. Tester, and anonymous reviewers for providing helpful comments on earlier versions of the manuscript. This research was supported through the NOAA South Florida Ecosystem Research and Monitoring Program, funded jointly by the National Marine Fisheries Service Southeast Fisheries Science Center and the National Ocean Service National Centers for Coastal Ocean Science. The views expressed herein are those of the authors and do not necessarily reflect the views of NOAA or any of its subagencies.

\section{References}

Brandt, S. B., and J. Kirsch. 1993. Spatially explicit models of striped bass growth rate potential in Chesapeake Bay. Transactions of the American Fisheries Society 122:845869.

Brett, J. R., and T. D. D. Groves. 1979. Physiological energetics. Pages 280-352 in W. S. Hoar, D. J. Randall, and J. R. Brett editors. Fish physiology, volume VIII. Bioenergetics and growth. Academic Press, New York.

Craig, J. F. 1977. The body composition of adult perch, Perca fluviatilis, in Windermere, with reference to seasonal changes and reproduction. Journal of Animal Ecology 46:617-632.

Deegan, L. A. 1986. Changes in body composition and morphology of young-of-the-year gulf menhaden, Brevoortia patronus Goode, in Fourleague Bay, Louisiana. Journal of Fish Biology 29:403-415.

Flath, L. E., and J. S. Diana. 1985. Seasonal energy dynamics of the alewife in southeastern Lake Michigan. Transactions of the American Fisheries Society 114:328-337.

Hartman, K. J., and S. B. Brandt. 1995. Estimating energy density of fish. Transactions of the American Fisheries Society 124:347-355.

Henderson, P. A., R. H. A. Holmes, and R. N. Bamber. 1988. Size-selective overwintering mortality in the sand smelt, Atherina boyeri Risso, and its role in population regulation. Journal of Fish Biology 33:221-233.

Hettler, W. F., Jr. 1989. Food habits of juveniles of spotted seatrout and gray snapper in western Florida Bay. Bulletin of Marine Science 44:152-165.

Johnson, T. J., D. M. Mason, S. T. Schram, and J. F. Kitchell. 1999. Ontogenetic and seasonal patterns in the energy content of piscivorous fishes in Lake Superior. Journal of Great Lakes Research 25:275-281.

Lantry, B. F., and D. J. Stewart. 1993. Ecological energetics of rainbow smelt in the Laurentian Great Lakes: an interlake comparison. Transactions of the American Fisheries Society 122:951-976.

Lantry, B. F., D. J. Stewart, P. S. Rand, and E. L. Mills. 1999. Evaluation of total-body electrical conductivity to estimate whole-body water content of yellow perch, Perca flavescens, and alewife, Alosa pseudoharengus. Fishery Bulletin 97:71-79.

Litvin, S. Y. 2005. Trophic linkages, movements, condition, and energetics of a juvenile marine transient in the Delaware Bay estuary: implications for the role of habitat in recruitment success. Doctoral dissertation. Rutgers University, New Brunswick, New Jersey. 
Love, R. M. 1980. The chemical biology of fishes, volume 2. Academic Press, London.

McCollum, A. B., D. B. Bunnell, and R. A. Stein. 2003. Cold, northern winters: the importance of temperature to overwinter mortality of age- 0 white crappies. Transactions of the American Fisheries Society 132:977-987.

Phillipson, J. 1964. A miniature bomb calorimeter for small biological samples. Oikos 15:131-139.

Post, J. R., and E. A. Parkinson. 2001. Energy allocation strategy in young fish: allometry and survival. Ecology 82:1040-1051.

Rand, P. S., B. F. Lantry, R. O'Gorman, R. W. Owens, and D. J. Stewart. 1994. Energy density and size of pelagic prey fishes in Lake Ontario, 1978-1990: implications for salmonine energetics. Transactions of the American Fisheries Society 122:977-1001.

Rand, P. S., and D. J. Stewart. 1998. Dynamics of salmonine diets and foraging in Lake Ontario, 1983-1993: a test of a bioenergetic model prediction. Canadian Journal of Fisheries and Aquatic Sciences 55:307-317.

Schmidt-Nielson, K. 1997. Animal physiology: adaptation and the environment, 5th edition. Cambridge University Press, New York.

Schreckenbach, K., R. Knosche, and K. Ebert. 2001. Nutrient and energy content of freshwater fishes. Journal of Applied Ichthyology 17:142-144.

Schultz, E. T., and D. O. Conover. 1997. Latitudinal differences in somatic energy storage: adaptive responses to seasonality in an estuarine fish (Atherinidae: Menidia menidia). Oecologia 109:516-529.

Schultz, E. T., and D. O. Conover. 1999. The allometry of energy reserve depletion: a test of a mechanism for sizedependent winter mortality. Oecologia 119:474-483.

Sogard, S. M. 1997. Size-selective mortality in the juvenile stage of teleost fishes: a review. Bulletin of Marine Science 60:1129-1157.

Sogard, S. M., and M. L. Spencer. 2004. Energy allocation in juvenile sablefish: effects of temperature, ration, and body size. Journal of Fish Biology 64:726-738.

Stewart, D. J., and F. P. Binkowski. 1986. Dynamics of consumption and food conversion by Lake Michigan alewives: an energetics modeling synthesis. Transactions of the American Fisheries Society 115:643-661.

Tanaka, M., S. Kawai, T. Seikai, and J. S. Burke. 1996. Development of the digestive organ system in Japanese flounder in relation to metamorphosis and settlement. Marine and Freshwater Behavior and Physiology 28:1931

Thayer, G. W., W. E. Schaaf, J. W. Angelovic, and M. W. LaCroix. 1973. Caloric measurements of some estuarine organisms. Fishery Bulletin 71:289-296.

Thompson, J. M., E. P. Bergersen, C. A. Carlson, and L. R. Kaeding. 1991. Role of size, condition, and lipid content in the overwinter survival of age-0 Colorado squawfish. Transactions of the American Fisheries Society 120:346353.

Trippel, E. A., O. S. Kjesbu, and P. Slemdal. 1997. Effects of adult age and size structure on reproductive output in marine fishes. Pages 31-62 in R. C. Chambers and E. A. Trippel editors. Early life history and recruitment in fish populations. Chapman and Hall, London.

Tzeng, M. W., J. A. Hare, and D. G. Lindquist. 2003. Ingress of transformation stage gray snapper, Lutjanus griseus (Pisces: Lutjanidae) through Beaufort Inlet, North Carolina. Bulletin of Marine Science 72:891-908.

Wuenschel, M. J., A. R. Jugovich, and J. A. Hare. 2004. Effect of temperature and salinity on the energetics of juvenile gray snapper (Lutjanus griseus): implications for nursery habitat value. Journal of Experimental Marine Biology and Ecology 312:333-347.

Yúfera, M., G. Parra, R. Santiago, and M. Carrascosa. 1999. Growth, carbon, nitrogen and caloric content of Solea senegalensis (Pisces: Soleidae) from egg fertilization to metamorphosis. Marine Biology 134:43-49. 